\title{
O LÍDER INOVADOR SEGUNDO A PERCEPÇÃO DE GESTORES INTERMEDIÁRIOS
}

\section{Patricia Fernanda Dorow}

Mestre em Engenharia e Gestão do Conhecimento pela Universidade Federal de Santa Catarina UFSC

patrciadorow@gmail.com (Brasil)

\section{Julieta Kaoru Watanabe Wilbert}

Mestre em Engenharia e Gestão do Conhecimento pela Universidade Federal de Santa Catarina UFSC

julieta.wuilbert@gmail.com (Brasil)

\section{Roseli Jenoveva Neto}

Mestre em Administração pela Universidade Federal do Rio Grande do Sul - UFRGS

Professora do Delinea Soluções Gráficas e Digitais Ltda.

rjn@unesc.net (Brasil)

\section{Gertrudes Aparecida Dandolini}

Doutora em Engenharia de Produção pela Universidade Federal de Santa Catarina - UFRGS

Professor da Universidade Federal de Santa Catarina - UFRGS

gtude@gmail.com (Brasil)

\section{RESUMO}

A atuação de um líder é fator crítico de sucesso para que a inovação ocorra em uma organização, e a percepção dos liderados com relação a traços vinculados a um perfil inovador em seu líder pode atuar como um fator propulsor para a inovação. O objetivo do presente estudo foi investigar as características de um líder inovador segundo a percepção de gestores intermediários em organizações consideradas inovadoras em Santa Catarina. Buscou-se verificar se os pesquisados percebem o seu gestor principal como um líder inovador. A abordagem da liderança como um processo social relacional enfatiza a relevância da percepção do gestor intermediário com relação ao líder principal, que influencia a forma como o primeiro vai se conduzir, por sua vez, no papel de líder. Os resultados mostram que comportamentos do líder inovador relatados na literatura são percebidos como muito importantes, e mesmo imprescindíveis para a condução de uma organização inovadora. Ainda que os resultados não possam ser generalizados, o estudo contribui para enfatizar a importância da percepção dos liderados com relação ao seu líder, confirmando que algumas características de liderança podem ser associadas ao líder inovador.

Palavras chave: Líder inovador; Inovação; Empresas inovadoras; Percepção de líder inovador; Características de líder inovador. 


\section{INTRODUÇ̃̃̃O}

Em outubro de 2013 a base de pesquisa Scopus registrava quase duzentos mil artigos publicados sobre inovação em contexto de organizações, sendo aproximadamente trinta mil entre 2012 e 2013, demonstrando o interesse da comunidade científica pelo tema. As organizações que não inovam correm o risco de perder a competitividade ou até mesmo de perecerem (Monteiro, 2005; Liao, Fei, \& Chen, 2007). Na organização inovadora, pessoas são o elemento central, dado que os processos de inovação são predominantemente centrados em trabalhos de grupos de pessoas com competências e talentos diferentes para criar coisas novas (Tidd, Bessant, \& Pavitt, 2008).

Inovar significa ir ao encontro de algo novo, e, portanto, buscar a mudança. No entanto, as pessoas são inerentemente resistentes à mudança: evitá-la ou resistir a ela é da natureza humana. Ainda que a resistência à mudança seja natural, não mudar pode ser mortal para a sustentabilidade da organização (Gilley, Gixon, \& Gilley, 2008).

O processo de inovação pode parecer caótico, aleatório e, portanto, de difícil entendimento. Entretanto, um olhar mais atento revela que certos elementos organizacionais e sociais são direcionadores da inovação. Junto com a estratégia organizacional, a liderança ocupa um papel central na condução da inovação, e as competências do líder na implementação da mudança são determinantes para que o processo de inovação aconteça (Tidd, Bessant, \& Pavitt, 2008; Gilley, Dixon, \& Gilley, 2008). Além do líder possuir a competência para implementar mudanças, é necessário que os seus liderados a reconheçam para que se comprometam com o direcionamento desejado pelo líder (Borgogni et al., 2011).

A presente pesquisa, motivada em investigar a percepção de liderados quanto às características de um líder inovador, utiliza-se da aplicação de um questionário com gestores intermediários de três empresas inovadoras em Santa Catarina segundo pesquisa divulgada em 2013, pela publicação brasileira de gestão, economia e negócios, Grupo Amanhã. Com isso, pretende-se identificar o grau de importância dada pelos respondentes a características do líder inovador, identificadas por meio de um instrumento de pesquisa validado por Monteiro $(2005 ; 2008)$ e por meio da adequação semântica realizada pelos autores.

Para atender a esse objetivo, o artigo apresenta na Seção 2 o embasamento teórico conceitual sobre liderança no contexto da inovação. Na Seção 3 são descritos os procedimentos metodológicos. A Seção 4 descreve os resultados e as discussões e finalmente, a Seção 5 apresenta as considerações finais da pesquisa.

Revista de Administração e Inovação, São Paulo, v. 12, n.3 p. 209-225, jul./set. 2015. 


\section{A LIDERANÇA NO CONTEXTO DA INOVAÇÃO}

A inovação enquanto processo de mudança intencional e benéfico para a organização requer múltiplas pessoas para transformar uma ideia criativa em algo comercializável no mercado (Monteiro, 2005; Tidd, Bessant, \& Pavitt, 2008), que necessita ser coordenado em direção aos resultados desejados. A coordenação ocorre por meio da liderança, que pode ser entendida como um processo de influenciar outros para atingir os resultados desejados (De jong, Den Hartog, 2007).

A liderança pode ser também compreendida como um processo social relacional entre líderes e liderados, em que o comportamento dos líderes influencia o comportamento dos liderados (idem), que decorrem da percepção dos últimos com relação ao comportamento dos primeiros (Monteiro, 2008; Waldman, Bass, 1991; Borgogni et al., 2011). Como exemplo desse fato, Borgogni et al., (2009) demonstraram que a percepção de empregados com relação a atributos de supervisores e líderes estratégicos no setor público italiano estão relacionados com a eficácia organizacional. Ou seja, os liderados se adequam às características do líder. Seguindo esse raciocínio, para que os liderados envidem seus esforços rumo à inovação em seus locais de trabalho, é necessário que eles percebam a sua liderança como sendo inovadora.

No contexto da inovação, o líder possui a tarefa de criar e manter um ambiente propício, de forma a conduzir os colaboradores a apresentarem comportamentos desejados (Tidd, Bessant, \& Pavitt, 2008; Monteiro, 2008). O papel do líder na esfera estratégica é ressaltado por Men (2012), quando afirma que a imagem do CEO percebida internamente influencia o comprometimento dos empregados. Os líderes no topo da pirâmide hierárquica são destacados também por Koulopoulos (2011, p.61):

"O único elemento consistente encontrado nas organizações que realmente sustenta a inovação é a liderança. Enquanto a inovação está profundamente enraizada em comportamentos ligados á cultura da organização, a licença e a autoridade para determinar o valor da inovação sempre começam a partir da liderança e, especificamente, nos níveis mais altos da hierarquia”.

Monteiro (2005) menciona a distinção do impacto do líder de acordo com o nível organizacional em que encontra: os líderes operacionais influenciam diretamente na motivação dos colaboradores por meio de seus comportamentos, ao passo que os líderes estratégicos influenciam os colaboradores mais próximos, que são líderes intermediários e operacionais.

Pressupondo-se que a inovação necessita de líderes que superem os obstáculos das resistências às mudanças, que características do líder são percebidas por liderados como necessárias para executar mudanças e dirigir a inovação em organizações?

Revista de Administração e Inovação, São Paulo, v. 12, n.3 p. 209-225, jul./set. 2015. 
Para entender o papel do líder no contexto de inovação, é oportuno trazer o conceito de inovação como sendo um processo que envolve etapas com características diferenciadas: geração de ideias, identificação de oportunidades, a seleção de ideias, o desenvolvimento e a implementação de ideias selecionadas e a sua comercialização após transformada em um novo produto ou serviço. Considerando estas etapas do processo de inovação, elas requerem diferentes tipos de liderança, são inseparáveis e complementares na determinação do sucesso do novo empreendimento (Rosing, Frese, \& Bausch, 2011).

A etapa conhecida como front-end trata da geração, seleção de ideias e identificação de oportunidades e vincula-se à noção de criatividade. O front-end requer líder com características de extrema abertura e curiosidade sobre o mundo externo, o pensamento out-of-the-box, paciência quanto aos resultados, a aceitação de riscos, vontade de experimentar e tolerância de falhas (Bel, 2010). Já as etapas após a seleção das ideias, chamada por alguns autores (Deschamps, 2005; Bel, 2010) de back end da inovação ensejam um líder voltado a gestão de processos e de projetos, com foco na implementação operacional, rapidez na decisão e ação, pragmático, habilidades de coordenação e, acima de tudo, uma grande vontade de vencer no mercado (Bel, 2010).

Espera-se, contudo, que o líder do front-end considere as implicações da escolha de sua tecnologia para que o novo produto tenha chances favoráveis na fase de implementação, e que o líder do back end mantenha a visão estratégica e os objetivos do novo produto para evitar um problema de mercado (Bel, 2010).

Um bom líder inovador é aquele que tem a capacidade de se sobressair perante as habilidades conflitantes da criatividade e da disciplina (Deschamps, 2005; Bel, 2010), reconhecendo as oportunidades, aceitando as incertezas, aprendendo com os erros. É importante que esse líder entenda que os prazos são eventos fundamentais, e decida como será estabelecido o cronograma para um projeto de inovação, e ainda, como esse prazo será transmitido aos envolvidos no projeto, bem como, a melhor forma de gerenciar o prazo para maximizar a criatividade inovadora (Halbesleben et al., 2003).

Nas organizações os líderes estão inseridos em uma cadeia hierárquica, sendo os líderes intermediários seguidores de um líder principal. A percepção dos líderes intermediários sobre o último, com relação a características inovadoras e como porta-voz da estratéia voltada para inovação, pode impactar no papel do gestor intermediário enquanto intérprete do discurso estratégico junto aos subordinados. (Monteiro, 2008, p.77), e por efeito em cadeia, influenciar a percepção dos colaboradores com relação aos seus gestores e ao líder principal.

De acordo com Waldman e Bass (1991), a percepção dos liderados com relação à liderança pode ser especialmente relevante durante a geração de ideias, nos momentos de falta de confiança e de 
inspiração na equipe. Isso pode ser percebido quando um líder propicia uma visão das possibilidades de inovação, ao mesmo tempo permitindo a autonomia e criatividade dos liderados na realização da visão organizacional. No entendimento dos autores Carmeli, Gelbard e Gefen (2010) quando o líder externaliza comportamentos associados à inovação, as pessoas se sentem motivadas a buscarem soluções para os problemas. Tais comportamentos, segundo os autores, são traduzidos por: encorajamento a iniciativas individuais, clarificação das responsabilidades, avaliações e feedbacks de desempenho, orientação firme com relação a tarefas, ênfase na qualidade das relações do grupo e demonstração de confiança aos membros da equipe.

Monteiro (2005, p.159) apresenta quatro dimensões de comportamentos do líder inovador, resultantes de uma pesquisa empírica sobre a percepção de subordinados em uma empresa de turismo em Portugal. São as dimensões:

a) Tomada de Decisão: o líder inovador apresenta firmeza e segurança nas tomadas de decisão, enfrentando os problemas sem adiar. Trata-se de uma pessoa dinâmica, empreendedora que gosta de seu trabalho;

b) Consideração: refere-se à interação do líder com o grupo. O líder inovador valoriza o trabalho do grupo, atribuindo-lhes os méritos. É alguém que motiva o indivíduo e o grupo;

c) Status: é uma dimensão relacional, onde se verifica a relação de igualdade que o líder estabelece com os seus liderados com relação a aspectos vinculados a hierarquia organizacional. O líder inovador estabelece relações de proximidade entre si e os liderados;

d) Flexibilidade: refere-se ao grau de resistência à modificação de métodos e padrões de trabalho. O líder inovador apresenta abertura a mudanças.

As quatro dimensões foram obtidas por meio de entrevistas com subordinados para identificar o que eles percebem como sendo comportamentos que caracterizam um líder inovador (e não inovador). A partir desse resultado a autora desenvolveu um questionário validado pela Análise Fatorial em Componentes Principais para reduzir o número de questões sem perda significativa de conteúdo, e empregou Alfa de Cronbach para validar a consistência interna, ou seja, a interrelação entre os itens de cada dimensão. O trabalho relatado em Monteiro (2005) serviu de subsídio para a tese da mesma autora em 2008, onde a metodologia encontra-se pormenorizada.

As características levantadas empiricamente por Monteiro (2005) encontram-se relatadas na literatura. Por exemplo, Gilley, Dixon e Gilley (2008) destacam seis habilidades e características de liderança para criar um ambiente propício a mudanças e à inovação: capacidade para se comunicar; 
capacidade para se motivar; capacidade de coaching (de conduzir pessoas); capacidade de promover o trabalho em equipe e colaboração; capacidade de oferecer recompensas. Deschamps (2005) menciona que o líder inovador aceita riscos e falhas, juntamente a um desejo de fazer sua equipe aprender com projetos que dão errado, tendo coragem de parar projetos quando for necessário. O mesmo autor enfatiza ainda que o líder inovador possui talento para criar e dirigir equipes vencedoras, para atrair e reter inovadores. Outras características mencionadas por Deschamps (2005) e que emergiram na pesquisa empírica de Monteiro (2005) são: a abertura para a aprendizagem contínua, abertura para ideias e tecnologias externas e alto grau de paixão pela sua missão e para a inovação, bem como para compartilhar sua paixão com o seu pessoal.

A liderança inovadora envolve, em suma, diferentes papéis e habilidades entre os diferentes níveis da organização, bem como orientações estratégicas ao longo da organização do processo de inovação (Rosing, Frese, \& Bausch, 2011).

Considerando que o líder é aquele que influencia os liderados por meio de um processo sociorrelacional (Monteiro, 2008), o reconhecimento dos liderados com relação a existência ou não de características e habilidades acima mencionadas no comportamento de seu líder está associada ao fomento de uma cultura organizacional voltada para a inovação: um exemplo é Steve Jobs, que simboliza o líder inovador da Apple (Davila, Epstein, \& Shelton, 2007). Diante deste contexto este estudo buscou, por meio da aplicação de questionário, conhecer a percepção dos gestores intermediários em relação a um líder inovador em três empresas inovadoras de Santa Catarina. Adicionalmente procurou-se saber se os gestores intermediários percebem seu líder principal como possuidor de características de um líder inovador.

\section{PROCEDIMENTOS METODOLÓGICOS}

A pesquisa pode ser caracterizada como descritiva quanto aos fins (Vergara, 2009). Foi utilizado o método de casos múltiplos proposto por Yin (2010) em três empresas consideradas inovadoras, publicação de 2013, como resultado projeto denominado Campeãs da Inovação, décima edição, realizado pelo Grupo Amanhã, fundado em 1986, publicação brasileira de gestão, economia e negócios. A pesquisa realizada pela revista foi em parceria com a consultoria especializada Edusys e com o apoio técnico da Fundação Dom Cabral. O instrumento de levantamento de dados utilizado foi um questionário respondido pelo Google.docs, portando, sem a identificação dos respondentes, objetivando investigar as características de um líder

Revista de Administração e Inovação, São Paulo, v. 12, n.3 p. 209-225, jul./set. 2015. 
inovador segundo a percepção de gestores intermediários em organizações consideradas inovadoras em Santa Catarina, e adicionalmente, verificar se os pesquisados percebem o seu gestor principal como um líder inovador. Por gestor intermediário definiu-se o profissional com pelo menos um subordinado, à exceção do $\mathrm{CEO}$, presidente ou equivalente. O universo foi constituído por gestores intermediários de três empresas de Santa Catarina consideradas inovadoras, pertencentes aos setores: (1) químico (tintas e vernizes), com 20 questionários respondidos; (2) empresa do setor de indústria têxtil com 5 retornos e; (3) empresa do setor metalúrgico (fixadores), com 4 questionários respondidos.

O questionário inicial foi estruturado em torno de quatro dimensões utilizadas por Monteiro (2008), são elas: tomadas de decisão, consideração, status e flexibilidade, constando 46 questões destinadas a obter respostas em uma escala de do tipo Likert variando de 0 (discordo completamente) a 5 (concordo plenamente). Devido à baixa confiabilidade de algumas perguntas, o questionário foi adaptado novamente.

O questionário final foi aplicado aos gestores intermediários e constou de 25 questões. Uma questão aberta foi adicionada para que o respondente acrescentasse algum comportamento que ele considerasse importante para um líder inovador e que não constasse no questionário. Também uma questão com resposta binária ( $\operatorname{sim} /$ não) perguntando se o respondente considera sua liderança maior, seja CEO, Presidente ou equivalente, como sendo inovador. A ferramenta para a tabulação dos dados utilizada foi o Excel. A fase da concepção teve por objetivo a definição do instrumento de pesquisa que foi o questionário elaborado por Monteiro (2005). Conforme explicado anteriormente, esse questionário utiliza quatro dimensões (tomadas de decisão, consideração, status e flexibilidade) por meio de uma escala do tipo Likert de 6 pontos, de 0 (discordo totalmente) até 5 (concordo totalmente). O questionário é formado por 25 afirmações referentes às quatro dimensões descritas anteriormente. Nesta etapa o questionário foi traduzido e na sequência realizada uma validação por pares.

O trabalho foi dividido em três etapas: concepção, pré-teste e aplicação. Na fase de pré-teste foi aplicado o instrumento (questionário) para avaliar se as perguntas estavam elaboradas de forma a não gerar interpretações equivocadas. Primeiramente o questionário foi aplicado pessoalmente pelas pesquisadoras, com o intuito de realizar a adequação de linguagem. Na sequência, pelo Google.docs foi realizado mais um de pré-teste, com funcionários (gestores e não-gestores) de uma empresa da região de Florianópolis, que responderem ao questionário e assim, buscou-se validar o entendimento das perguntas. O critério de escolha da empresa foi a acessibilidade aos respondentes. Na análise dos dados coletados observou-se que alguns itens seriam desnecessários. Posteriormente, foi feita a adaptação do questionário com o apoio de dois especialistas da área qualitativa. Desta forma, obteve-se a versão final do instrumento.

Revista de Administração e Inovação, São Paulo, v. 12, n.3 p. 209-225, jul./set. 2015. 
$\mathrm{Na}$ terceira fase, chamada de aplicação, foi definida a amostra que contou com 29 gestores intermediários nas empresas-alvo deste estudo. O questionário foi aplicado na segunda quinzena de novembro de 2013. O contato inicial com o gestor intermediário das empresas selecionadas foi realizado pelas pesquisadoras para explicar o objetivo da pesquisa, convidar a empresa a participar, bem como dirimir quaisquer dúvidas. Ao receber o aceite foi, então, solicitada a colaboração do gestor para a sensibilização e o encaminhamento da pesquisa aos colaboradores para que estes respondessem o questionário diretamente pelo Google .docs. No e-mail foi incluído um link para o Google Docs, que remetia ao questionário a ser preenchido.

\section{RESULTADOS E DISCUSSÕES}

Das 25 descrições de comportamento propostas por Monteiro (2005; 2008), 23 foram consideradas como muito importantes (4 na escala de Likert) ou imprescindíveis (5 na escala de Likert) para um líder inovador para $80,8 \%$ dos respondentes.

A seguir explicita-se os resultados por dimensões, apresentando as características que obtiveram acima de $80 \%$ de respondentes que indicaram os índices 4 ou 5 da escala de Likert. As Figuras 1 a 5 explicitam as características avaliadas pelos respondentes.

Monteiro $(2005 ; 2008)$ define a dimensão Tomada de Decisão com atributo associados à firmeza nas decisões, aberto à aprendizagem e ao novo, autoconfiante, dinâmico e rápido na compreensão de novas situações e demonstrando gostar do que faz. A Figura 1 apresenta os resultados da pesquisa para essa dimensão. 


\section{Figura 1}

Número de respondentes que atribuem como sendo importantes ou muito importantes a características associadas à dimensão Tomada de Decisão.

\section{Torrada de Decisão}

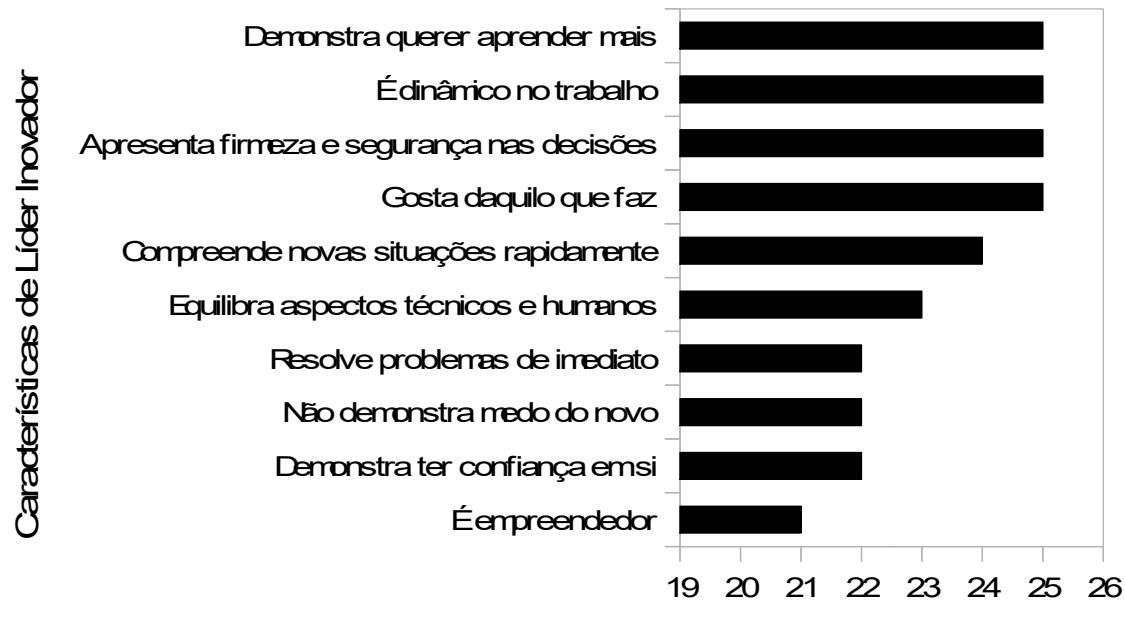

Número de respondentes

Fonte: Dados da pesquisa, 2013.

Para mais de $80 \%$ dos respondentes da pesquisa das empresas catarinenses selecionadas, todas as características elencadas para a dimensão Tomada de Decisão foram consideradas muito importantes ou imprescindíveis para um líder inovador. Algumas delas são também apontadas por Deschamps (2005) como sendo igualmente muito importantes ou imprescindíveis para o líder inovador: o sentido de missão e paixão pelo que faz (gosta daquilo que faz), e a abertura para a aprendizagem contínua destacam-se junto com características que se espera de um líder que deve acompanhar as evoluções na sociedade. A percepção de que o líder é dinâmico associa-se à própria ideia de que para ser inovador, é preciso sair na frente dos concorrentes, pois a competição no mercado traz consigo a ideia de velocidade (Wang \& Wang, 2012). Um aspecto destacado pelos respondentes se refere ao fato de o líder apresentar firmeza e segurança nas decisões. Esse fato encontra eco em Davila (2007, p. 266), que menciona que os seguidores devem sentir um claro sentido de comando por parte do líder, sobretudo nos momentos cruciais em que deve ser decidido por um ou outro caminho ao longo de um processo de inovação.

Se considerarmos as características predominantes para o líder de front end ou back end da inovação mencionado por Bel (2010), observa-se na Figura 1 que para os respondentes as 
características do líder back end parecem predominar como mais relevantes para os liderados. Ainda que características como ser empreendedor, não ter medo do novo, resolver os problemas com rapidez, tenham sido considerados como muito importantes ou imprescindíveis para o líder inovador, eles se apresentam ligeiramente com menor índice de relevância com relação às demais características da dimensão Tomada de Decisão.

Relativo à dimensão Consideração, que Monteiro (2005; 2008) define como sendo a dimensão referente à interação do líder com o grupo, foram consideradas muito importantes ou imprescindíveis para o líder inovador as características apresentadas na Figura 2.

\section{Figura 2}

Número de respondentes que atribuem como sendo importantes ou muito importantes a características associadas à dimensão Consideração

\section{Consideração}

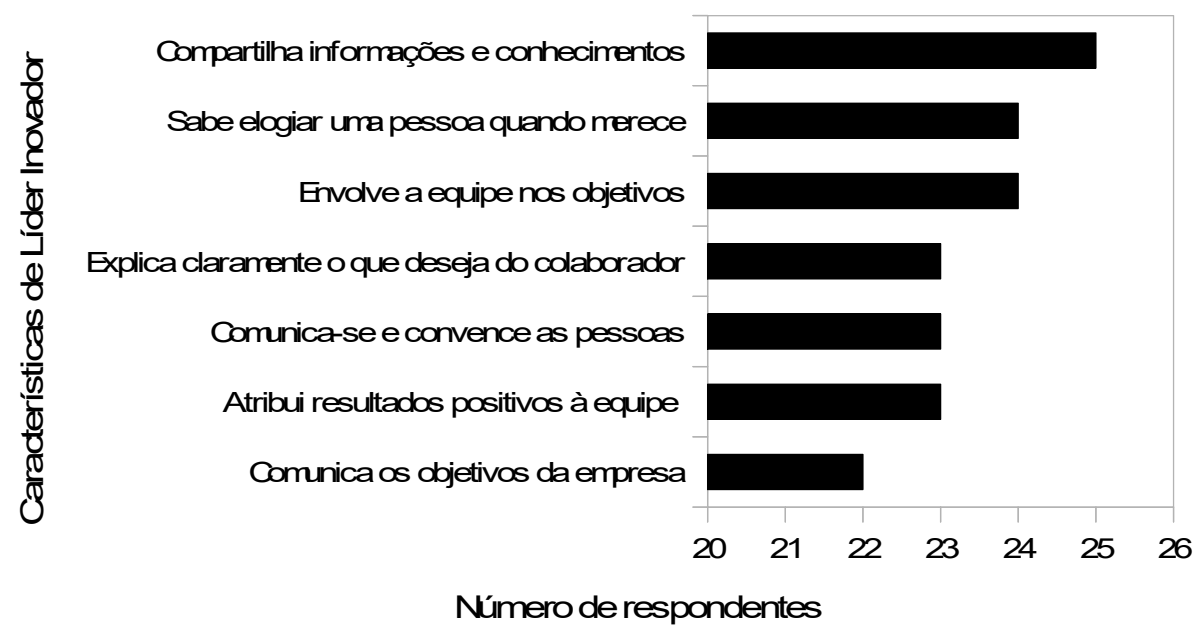

Fonte: Dados da pesquisa, 2013.

As características apresentadas na Figura 2 receberam os índices 4 e 5 na escala de Likert, por mais de $80 \%$ dos respondentes. Observa-se que tratam de aspectos relacionados à comunicação oral e contato interpessoal do líder com o colaborador. Embora não tratem de atributos exclusivos de um líder inovador, as características relativas à dimensão Consideração são essenciais na construção de um clima organizacional que favoreça a inovação, e aspectos de relações interpessoais são decisivos (Gilley, Dixon, \& Gilley, 2008).

Com relação à atitude de comunicar os objetivos da empresa aos colaboradores, os dados surpreenderam com um número representativo de respondentes $(15,4 \%)$ que considerou ser indiferente como característica de um líder inovador. A priori, esse resultado parece ser contraditório relacionando 
à característica considerada como relevante: compartilha informações e conhecimentos. Uma justificativa, ainda que em nível de inferência, poderia ser de natureza contextual: em um ambiente onde os objetivos da empresa são disseminados por meio de redes internas (intranet) ou meios impressos podem prescindir de uma comunicação mais direta da liderança especificamente à comunicação de objetivos organizacionais.

Uma característica da dimensão Consideração que obteve 19,23\% de respondentes, avaliada como sendo indiferente e 3,85\% como característica sem importância para um líder inovador está relacionada ao incentivo deste para que seus liderados expressem opiniões contrárias. Esse fato pode indicar um aspecto cultural e social: haveria influência de um componente frequentemente falado nos círculos informais em organizações brasileiras: manda quem pode, obedece quem tem juízo? Por não se tratar do escopo deste estudo, tais elementos contextuais são aqui apresentados a título de sugestões de estudos na área da cultura em organizações.

A dimensão Status ou Igualdade é conceituada por Monteiro (2005) como sendo de natureza relacional, verificando se o líder estabelece uma relação de igualdade com os subordinados, transcendendo os aspectos ligados à formalização da hierarquia, minimizando as distâncias entre si e os demais. Os resultados da pesquisa para essa dimensão são apresentados na Figura 3.

\section{Figura 3}

Índice de respondentes que atribuem como sendo importantes ou muito importantes a características associadas à dimensão Status e Igualdade

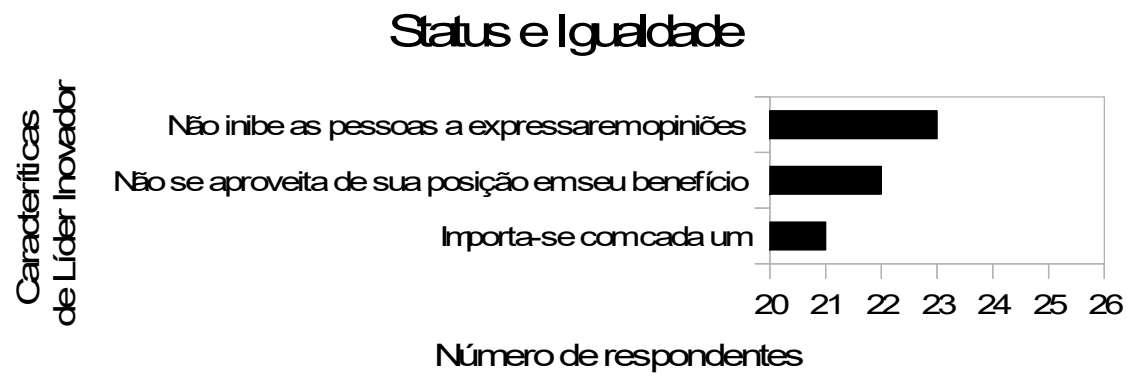

Fonte: Dados da pesquisa, 2013.

A Figura 3 demonstra que o grupo pesquisado valoriza o fato de o líder demonstrar proximidade com os liderados, sobretudo dando espaço para que as pessoas expressem suas opiniões, sem que se sintam inibidas. Também são relevantes os comportamentos do líder com relação a não tirar proveito próprio de sua posição e demonstrar que se importa com cada pessoa dentre os seus liderados. Essas percepções confirmam o fato de que a inovação necessita de cultura de valorização do 
conhecimento e da pessoa, por meio da promoção da espontaneidade e ausência de julgamentos sobre o que e como os liderados expressam as suas opiniões (Baskerville \& Dulipovici, 2006).

Com relação ao líder dispensar ou não a sinais indicativos de status (ex. vaga coberta, estacionamento, elevador ou restaurante exclusivo) $53,85 \%$ consideram ser indiferente como característica de um líder inovador.

A quarta dimensão identificada por Monteiro (2005; 2008) é a Flexibilidade, entendida como sendo a abertura para modificações de métodos de trabalho e a mudanças. A Figura 4 apresenta as características do líder inovador relacionadas a essa dimensão que são importantes ou muito importantes:

\section{Figura 4}

Índice de respondentes que atribuem como sendo importantes ou muito importantes a características associadas à dimensão Flexibilidade

\section{Flexibilidade}

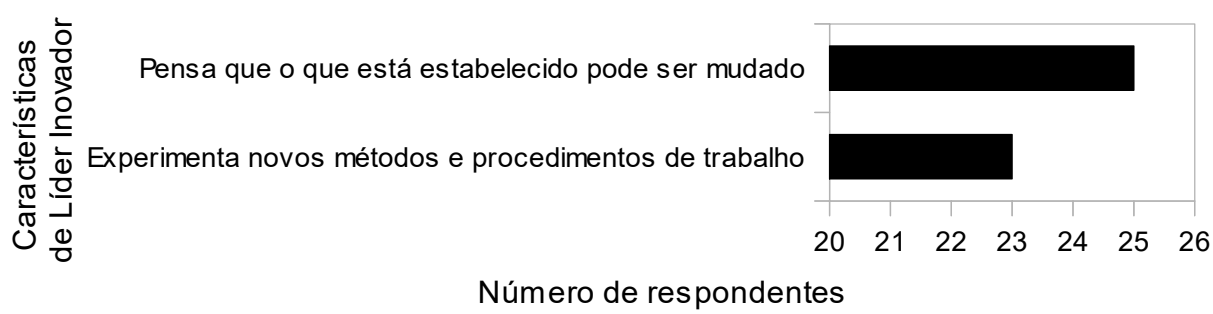

Fonte: Dados da pesquisa, 2013.

Para os respondentes das empresas catarinenses pesquisadas, a abertura para mudanças de métodos, regras de trabalho ou algo estabelecido são características de líderes inovadores. De fato, inovação está associada a mudanças e o líder inovador tem o papel de conduzir mudanças de forma adequada a quebrar as resistências (Gilley, Dixon, \& Gilley, 2008).

De forma geral, quase todas as características elencadas nas Figuras de 1 a 5 foram consideradas muito importantes ou imprescindíveis na percepção dos respondentes. Excetuaram-se a essa regra as características relativas à dimensão Status ou Igualdade. Em perguntas relativas a externalização de status pelo líder, 53, 85\% dos respondentes opinaram como sendo sem importância ou pouco importante o líder dispensar sinais externos de status, como por exemplo vaga de estacionamento exclusiva. Diante da questão: Para o líder inovador, a sigla Dr ou Eng, é sem importância e ter status lhe é indiferente, 61,54\% das respostas explicitam não ser relevante o comportamento do líder com relação a titulação pessoal ou status. Essa percepção pode ser decorrente de aspectos educacionais: no sul do país, o número de graduados em universidades é um dos maiores 
no Brasil, fazendo com que uma titulação universitária não represente necessariamente um símbolo de status.

De todas as dimensões destacam-se a Tomada de Decisão e a Consideração como sendo aquelas que obtiveram índice acima de 90\% na maioria das questões. De acordo com Gilley, Dixon e Gilley (2008) as características de liderança que promovem a inovação e que se encontram alinhadas as duas dimensões de Monteiro (2005) citadas acima, enfatizam a comunicação, motivação, coaching, promoção de trabalho em equipe, reconhecimento e influência na cultura e ambiente organizacional.

Solicitados, por meio de uma pergunta aberta ao final do questionário, a mencionarem características importantes que não tivessem contemplado no questionário, destaca-se algumas avaliadas com sendo complementares ao questionário, a exemplo de: conceder autonomia às pessoas, compartilhar conhecimentos e influenciar pessoas, ser confiável, desafiar a organização e suas equipes, possuir visão sistêmica, fazer gestão por conhecimento, valorizar talentos, saber ouvir, dar e receber feedback e ser positivo.

Embora não seja um atributo de característica de uma pessoa, fazer gestão do conhecimento sinaliza que há uma consciência por parte do respondente de que o líder inovador deve se preocupar com o tema, pois a gestão do conhecimento produz um ambiente que alavanca a inovação (Du Plessis, 2007), sobretudo criando um clima organizacional favorável ao compartilhamento do conhecimento entre as pessoas da organização (Lin, 2007). O papel da liderança nesse contexto é o de promover um ambiente de abertura de ideias e de comunicação (Lin \& Lee, 2006).

Nesse grupo de características mencionadas em resposta à pergunta aberta, emergem as mencionadas por Carmeli, Gelbard e Gefen (2010): avaliações e feedbacks de desempenho e por Waldmann e Bass (1991): conceder autonomia como características de um líder inovador.

Quando perguntados se consideram o CEO, Presidente ou equivalente de sua empresa como líder inovador, 24 dos 26 respondentes manifestaram afirmativamente, podendo isso ser um indicador confirmatório de colocação encontrada em literatura de que o líder estratégico percebido como inovador pelos liderados influencia na performance e na busca pela inovação dos componentes da organização (Waldman \& Bass, 1991; Monteiro, 2008; Carmeli; Gelbard, \& Gefen, 2010).

\section{CONSIDERAÇÕES FINAIS}

Inovar é uma questão de sobrevivência e sustentabilidade das organizações em um contexto de alta competitividade no mercado, e o líder tem o papel de conduzir a organização rumo a um ambiente 
propício à inovação, motivando as pessoas a trabalharem nessa direção. Entendendo a liderança como um processo relacional entre líder e liderados, a percepção destes últimos com relação ao primeiro influencia na motivação para a inovação. Ou seja, líderes percebidos como inovadores influenciam positivamente para que os liderados cooperem com a inovação nas organizações.

Para investigar essa premissa, o presente estudo buscou identificar as características de um líder inovador segundo a percepção de gestores intermediários de três organizações consideradas inovadoras em Santa Catarina. Esse público-alvo foi selecionado com base na afirmação de que, eles enquanto líderes para as posições operacionais são liderados pelos líderes estratégicos. Dessa forma, a percepção desse público-alvo, a priori, contempla a experiência enquanto líder e liderado, tornando as respostas mais realistas de acordo com a vivência na organização em que atua. A partir de um estudo empírico realizado no setor de turismo do Algarve, Portugal, por Monteiro (2005; 2008), o presente estudo adaptou para o contexto catarinense o questionário elaborado e validado pela pesquisadora lusitana, aplicando o instrumento de pesquisa a gestores intermediários das empresas catarinenses selecionadas.

Os resultados mostraram que as características levantadas por Monteiro $(2005 ; 2008)$ na área de serviços de turismo são válidas para o contexto de três indústrias de diferentes setores de Santa Catarina. A pesquisa também sugere que a percepção dos respondentes com relação ao seu líder maior pode ter correlação com o fato de as empresas serem inovadoras, a partir do fato de que o líder principal sendo percebido como inovador, isso promove a cultura da inovação na organização.

A contribuição do presente estudo consiste em enfatizar a importância da percepção dos liderados com relação ao seu líder, confirmando que algumas características de liderança são associadas ao líder inovador. Do ponto de vista prático para as organizações, o conhecimento dessas características pode auxiliar na elaboração de cursos de desenvolvimento gerencial e coaching para líderes.

Como limitação do estudo se se pode citar que os resultados não são generalizáveis, por estarem altamente vinculados a contexto organizacional, sua cultura e cultura da região onde se encontram as empresas pesquisadas. Ressalta-se que a mesma pesquisa pode apresentar resultados diferentes se aplicada em empresas inovadoras de outras regiões do Brasil.

Adicionalmente, o número de empresas e o número de respondentes não são suficientes para afirmações conclusivas. Contudo, o estudo acima relatado sugere a convergência de percepções com relação às características de um líder inovador de dois contextos distintos: de um lado, a percepção de colaboradores portugueses de empresas de um setor de serviços em Portugal, e do outro, de gestores intermediários em empresas do setor de indústrias do sul Catarinense, tendo por diferencial o fato de estas últimas serem consideradas inovadoras em 2012.

Revista de Administração e Inovação, São Paulo, v. 12, n.3 p. 209-225, jul./set. 2015. 
Finalmente, embora o questionário de pesquisa tenha sido fundamentado no trabalho de Monteiro (2008), o instrumento de coleta da presente pesquisa incorporou várias alterações decorrentes das fases de pré-teste. Somadas ao fato de não ter sido utilizado o método das grelhas de Kelly com construtos bipolares, conforme pesquisa de Monteiro (2005; 2008), e o público-alvo da autora portuguesa ter sido os subordinados, esses fatos inviabilizam a comparação entre os resultados obtidos em Portugal e em Santa Catarina, Brasil.

Ainda assim, verificou-se uma convergência de percepção dos respondentes nas pesquisas portuguesa e brasileira, podendo vir a corroborar com os autores que defendem que a liderança é um fenômeno relacional, e que influenciam por sua vez o fenômeno da inovação nas organizações.

Sugerem-se estudos buscando a generalização dos resultados por meio da aplicação do instrumento de pesquisa em vários outros contextos (setor público, por exemplo), com maior número de organizações e respondentes, buscando identificar as características de um líder inovador que devem ser percebidas pelos liderados, incluindo os colaboradores que não tenham funções de liderança. O conhecimento das características do líder inovador pode trazer elementos importantes para delinear ações de formação e desenvolvimento de líderes que inspirem seus seguidores a crerem e a atuarem para a concretização de uma cultura para inovação da organização.

\section{REFERENCIAS}

Baskerville, R., \& Dulipovici, A. (2006). The theoretical foundations of knowledge management. Knowledge Management Research \& Practice, (4), 83-105.

Borgogni, L., Dello Russo, L., \& Latham, G. (2011). The relationship of employee perceptions of the immediate supervisor and top management with collective efficacy, Journal of Leadership and Organizational Studies, SAGE, (18), 5-13.

BorgognI, L., Dello Russo, S., Petitta, L., \& Latham, G. (2009). Collective efficacy and organizational commitment in an Italian city hall, European Psychologist, (14), 363-371.

Bel, R. (2010). Leadership and Innovation: learning from the best. Global Business and Organizational Excellence, (29), 47-60.

Carmeli A., Gelbard R., \& Gefen, D.(2010). The importance of innovation leadership in cultivating strategic fit and enhancing firm performance. The Leadership Quarterly, (21), 339-349.

Davila, T., Epstein, M.J., \& Shelton, R. (2007) As regras da inovação. Trad. Rubenisch, R. Porto Alegre: Bookman, 336p. 
Deschamps, J-P. (2005) Different leadership skills for different innovation strategies. Strategy and leadership, (33), 31-38.

De Jong \& Den Hartog, D.N. (2007) Show leaders influence employees' innovative behavior. European Journal of Innovation Management, (10), 41-64.

Du Plessis, M. (2007) The role of knowledge managemente in innovation. Journal of Knowledge Management, (11), 20-29.

Gilley, A., Dixon, P., \& Gilley, J .(2008) Characteristics of Leadership Effectiveness: Implementing Change and Driving Innovation in Organizations. Human Resource Development Quarterly, (19), 153-169.

Halbesleben J.R.B., Novicevic, M.M., Harvey, M.G., \& Buckley, M.R. (2003) Awareness of temporal complexity in leadership of creativity and innovation: A competency-based model. The Leadership Quarterly, (14), 433-454.

Koulopoulos, T.M. (2011) Inovação com resultado: o olhar além do óbvio. Editora Gente/Editora Senac. São Paulo, 215 p.

Liao, S-H., Fei, W-C., \& Chen, C-C. (2007) Knowledge sharing, absorptive capacity, and innovation capability: an empirical study of Taiwan's knowledge-intensive industries. Journal of Information Science, (33), 340-359.

Lin, H-F. \& Lee, G-G. (2006) Effects of socio-technical factors on organizational intention to encourage knowledge sharing. Management Decision, (.44), 74-88.

Lin, H-F., Knowledge sharing and firm innovation capability: an empirical study. Inernational Journal of Manpower, v. 28,. n. 3/4, p.315-332, 2007.

Men, L.R. (2012) CEO credibility, perceived organizational reputation, and employee engagement. Elsevier. Public Relations Review, (38), 171- 173.

Monteiro, I. Percepção dos comportamentos do líder inovador pelos seus subordinados. Revista Encontros Científicos, (1), 152-160.

Monteiro, I. A. P. (2008) Comportamentos do líder inovador no sector do turismo. 2008. 376 p. Tese de doutorado em Psicologia das Organizações na Faculdade de Ciências Sociais e Humanas da Universidade do Algarve. Faro/Portugal.

Rosing, K., Frese, M., \& Bausch, A. (2011) Explaining the heterogeneity of the leadership-innovation relationship: Ambidextrous leadership. Elsevier.

Tidd, J., Bessant, J, \& Pavitt, K. (2008) Gestão da inovação. Tradução Elisamari Rodrigues Becker, Bookman, 3.ed, Porto Alegre, 302p. .

Trott, P. (2012) Gestão da inovação e desenvolvimento de novos produtos. Tradução Patricia Lessa Flores da Cunha; revisão técnica Paulo Antonio Zavislak, 4. ed., Porto Alerge: Bookman, 621p.

Vergara, S. C. (2009) Projetos e relatórios de pesquisa em administração. 11. ed. São Paulo: Atlas, 94 p. 
Waldman, D. A., \& Bass, B.M. (1991) Different phases of the innovation process. The Journal of High Technology Management Research, (2), 169-180.

Wang, Z., \& Wang, N. (2012) Knowledge sharing, innovation and firm performance. Expert Systems with Applications, (39), 8899-8908.

Yin, R.K. (2010) Estudo de caso: planejamento e métodos. 4. Ed. Porto Alegre: Bookman, 248 p.

\title{
THE INNOVATIVE LEADER ACCORDING TO THE PERCEPTION OF MIDDLE MANAGEMENT
}

\begin{abstract}
The role of a leader is a key factor for successful innovation in an organization, and the perception of followers with respect to the traits linked to an innovative profile of their leader can act as a driving factor for innovation. The purpose of this study was to investigate the characteristics of an innovative leader as perceived of middle managers in organizations considered innovative in Santa Catarina. Furthermore the study sought to determine whether the respondents perceive their principal manager as an innovative leader. The assumption of leadership being a social and relational process emphasizes the importance of the perception of the manager of the intermediate level in relation to the primary leader, because this influences the way the former will conduct himself in his role as leader. The results show that behavioral manners of innovative leaders, as reported in literature, are perceived to be very important, and even to be indispensable for managing an innovative organization. Although the results cannot be generalized, the study contributes to emphasize the importance of the perception of followers with respect to their leader, and so confirming that some leadership characteristics can be associated with the innovative leader.
\end{abstract}

Keywords: Innovative Leader; Innovation; Innovative companies; Perception of the innovative leader; Features of the innovative leader.

Data do recebimento do artigo: 15/08/2014

Data do aceite de publicação: 10/04/2015

Revista de Administração e Inovação, São Paulo, v. 12, n.3 p. 209-225, jul./set. 2015. 